TẠP CHÍ KHOA HỌC ĐẠI HỌC TÂN TRÀO

ISSN: $2354-1431$

http://tckh.daihoctantrao.edu.vn/

\title{
Nghiên cứu đặc điểm nông sinh học của giống bưởi Xuân Vân tại tỉnh Tuyên Quang
}

\author{
Vi Xuân Học ${ }^{a *}$; Nguyễn Quốc Hùng ${ }^{b}$; Phạm Thị Mai Trang ${ }^{a}$ \\ ${ }^{a}$ Truò̀ng Đại học Tân Trào \\ ${ }^{b}$ Viện nghiên cúu rau quả \\ *Email:hocvibm@gmail.com
}

\section{Thông tin bài viết}

Ngày nhận bài:

11/10/2017

Ngày duyệt đăng:

$10 / 3 / 2018$

\section{Tù̀ khoá:}

Bười Xuân Vân; đặc điểm nông sinh học.

\section{Tóm tắt}

Bưởi Xuân Vân có xuất xứ tại thôn Soi Hà, xã Xuân Vân, huyện Yên Sơn, tỉnh Tuyên Quang. Hiện nay bưởi Xuân Vân đã phát triển thành vùng bưởi đặc sản của tỉnh Tuyên Quang. Để có những căn cứ khoa học và xác định ra các biện pháp kỹ thuật phù hợp nhằm nâng cao năng suất, chất lượng bưởi Xuân Vân một cách hiệu quả và bền vững; việc nghiên cứu đặc điểm nông sinh học trên giống bưởi Xuân Vân là hết sức cần thiết. Kết quả nghiên cứu về đặc điểm nông sinh học năm 2015 - 2016 cho thấy: Bưởi Xuân Vân có chiều cao cây: 611,8 - 677,5 cm; đường kính tán: 704,5 - 715,5 cm; đường kính gốc: 16,99 $17,05 \mathrm{~cm}$. Thời thời gian từ khi nở hoa đến tắt hoa kéo dài từ 22 đến 27 ngày. Thời điểm thu hoạch từ cuối tháng 9 đầu đến tháng 10 . Trọng lượng quả: 0,906 - 0,912 kilogam/quả; số lượng quả: 96,5 -142,3 quả/cây; năng suất: 88,0 $128,9 \mathrm{~kg} /$ cây; số hạt: 122,9 - 124,6 hạt/quả; số múi: 13,4 -13,43 múi/quả; độ Brix: 10,93 - 10,97\%; tỷ lệ phần ăn được: 52,4 - 53,2\%.

\section{1. Đặt vấn đề}

Tuyên Quang là một trong những tỉnh nằm ở trung du miền núi phía Bắc có điều kiện sinh thái phù hợp với các giống cây ăn quả có múi, trong đó nổi tiếng nhất là giống Cam Sành Hàm Yên đượcxếp hạng “Thương hiệu vàng Nông nghiệp Việt Nam năm 2015”.Trong những năm gần đây, bên cạnh sự phát triển mạnh của giống cam sành Hàm Yên, tỉnh Tuyên Quang đã tập trung phát triển các giống cây ăn quả khác như: bưởi Diễn, cam Vinh, cam Đường Canh, trong đó đã hình thành được vùng trồng bưởi Xuân Vân tại xã Xuân Vân huyện Yên Sơn.

Bưởi Xuân Vân có nguồn gốc tại thôn Soi Hà, xã Xuân Vân, được trồng từ năm 1969, là giống bưởi ngọt chín sớm. Theo Cục Thống kê tỉnh Tuyên Quang, năm 2016, tỉnh Tuyên Quang hiện có 1362,61 ha bưởi, trong đó diện tích bưởi Xuân Vân chiếm khoảng 40\% diện tích (khoảng 550 ha). Đặc điểm nổi bật nhất của bưởi Xuân Vân là cao cây, diện tích tán lá lớn, ra hoa sớm và cho thu hoạch sớm, điều này rất có lợi bởi vì sau khi thu hoạch xong cây có thời gian phục hồi để ra hoa đậu quả vào năm sau, cây lâu bị già cỗi.

Hiện nay bưởi Xuân Vân đang tiếp tục được các cấp, các ngành của tỉnh Tuyên Quang quan tâm đầu tư quy hoạch tạo vùng sản xuất bưởi hàng hoá tập trung chuyên canh quy mô lớn. Vì vậy, những nghiên cứu chuyên sâu để xác định ra các biện pháp kỹ thuật phù hợp nhằm nâng cao năng suất và chất lượng đối với sản xuất bưởi Xuân Vân hiện nay tại tỉnh Tuyên Quang là hết sức cần thiết.

\section{Vật liệu, nội dung và phương pháp nghiên cứu}

\subsection{Vật liệu nghiên cúu}

Giống bưởi XuânVân: 9-10 năm tuổi đã cho năng suất ổn định, được trồng trên cùng một vườn có cùng chế độ chăm sóc như nhau.

\subsection{Nội dung và phwơng pháp nghiên cứu}

\subsubsection{Phương pháp bố trí thí nghiệm}

Thí nghiệm được bố trí trên vườn có độ tuổi: 9-10 tuổi. Chọn 10 cây đồng đều, ổn định về sinh trưởng, thí nghiệm theo dõi trong 2 năm; năm 2015 và năm 2016. 


\subsubsection{Chi tiêu và phuoong pháp theo dõi}

\subsubsection{1. Đặc điểm hình thái cây}

Mô tả đặc điểm thực vật học theo tài liệu hướng dẫn của Viện Tài nguyên Di truyền thực vật Quốc tế (IPGRI) ban hành năm 1999. Các chỉ tiêu mô tả: Tuổi cây, hình dạng tán cây, cách phát triển của cây, mật độ cành, bề mặt của thân cây, góc phân cành, hình thức nhân giống.

\subsubsection{2. Đặc điểm thân cành}

- Chiều cao cây $(\mathrm{cm})$ : Đo từ mặt đất đến vị trí cao nhất của cây.

- Chiều rộng tán $(\mathrm{cm})$ : Đo ở vị trí rộng nhất của tán cây theo 2 hướng Đông - Tây, Nam - Bắc.

- Đường kính gốc $(\mathrm{cm})$ : Đo trên thân chính cách mặt đất $20 \mathrm{~cm}$.

- Đường kính cành cấp $\mathrm{I}(\mathrm{cm})$ : Đo cách gốc cành cấp I $1 \mathrm{~cm}$.

- Độ cao phân cành cấp I $(\mathrm{cm})$ : Đo sát mặt đất đến góc phân cành cấp I thứ nhất.

- Số cành cấp I, cấp II: Đếm toàn bộ số lượng cành cấp $I$ và cành cấp $I I / c a ̂ y$.

* Các chỉ tiêu theo dõi trong 2 năm và lấy giá trị trung bình.

\subsubsection{3. Đặc điểm hình thái lá}

Mô tả theo tài liệu hướng dẫn của Viện Tài nguyên Di truyền thực vật Quốc tế (IPGRI) ban hành năm 1999, đo đếm và mô tả thực hiện một lần khi lá đã thành thục, vị trí lá lấy ở lá thứ 4 và thứ 5 , mỗi cây mô tả 10 lá.

- Các chỉ tiêu đo đếm: Chiều dài phiến lá $(\mathrm{cm})$, chiều rộng phiến lá $(\mathrm{cm})$, chiều dài eo lá $(\mathrm{cm})$, chiều dài cuống lá $(\mathrm{cm})$, tỷ lệ chiều dài/chiều rộng phiến lá, tỷ lệ chiều dài/chiều rộng eo lá.

- Các chỉ tiêu mô tả: Mầu sắc lá, mép lá, hình dạng và đầu lá.

\subsubsection{4. Đặc điểm hình thái hoa}

Mỗi cây thu 30 hoa đếm số chỉ nhị số cánh hoa sau đó lấy giá trị trung bình, mô tả thực hiện một lần vào thời điểm cây ra hoa, các chỉ tiêu theo dõi về hoa thực hiện trong 2 năm.

- Các chỉ tiêu mô tả: Mầu sắc hoa, dạng hoa, thời gian xuất hiện nụ (khi có $10 \%$ nụ xuất hiện); thời gian xuất hiện hoa (khi có $10 \%$ hoa nở). Thời gian hoa rộ (khi có $50 \%$ hoa nở). Thời gian kết thúc nở hoa (khi có $80 \%$ hoa nở), thời gian từ nở đến kết thúc nở hoa (ngày).

+ Các chỉ tiêu đo đếm: Số cánh hoa/hoa, số chỉ nhị/hoa, đường kính và chiều dài hoa.
2.2.2.5. Đặc điểm hình thái quả, năng suất và một số chỉ tiêu trên quả

- Đặc điểm hình thái: Mô tả hình dạng quả, mầu sắc quả, trục quả, mầu sắc tép, độ giòn của tép, độ bám của vỏ múi với tép, đánh giá cảm quan.

- Thời vụ thu hoạch: Theo dõi thời điểm khi quả chín.

- Các chỉ tiêu trên quả: Đo đếm các chỉ tiêu của 30 quả.

+ Chiều cao quả $(\mathrm{cm})$ : Đo từ đỉnh đến gốc quả theo chiều song song với trục quả.

+ Đường kính quả $(\mathrm{cm})$ : Đo ở vị trí rộng nhất của quả.

+ Số (múi/quả): Đếm tổng số múi/tổng số múi tách ra khỏi quả.

+ Số (hạt/quả): Đếm tổng số hạt/quả tách hạt.

+ Khối lượng phần ăn được (khối lượng thịt quả): Bóc 30 quả, cân tính giá trị trung bình của khối lượng phần ăn được tính theo công thức:

\begin{tabular}{|l|r|r|}
\hline \multirow{3}{*}{$\begin{array}{l}\text { Tỷ lệ thịt } \\
\text { quả } \%=\end{array}$} & Trọng lượng quả $(\mathrm{g})$ - Trọng lượng vơ $(\mathrm{g})$ - Trọng lượng hạt $(\mathrm{g})$ & \multirow{2}{*}{ x 100} \\
\cline { 2 - 3 } & Trọng lượng qua $(\mathrm{g})$ & \\
\hline
\end{tabular}

- Phân tích thành phần của quả:

+ Độ brix (\%): Đo bằng cách ép lấy dịch quả và đo ngay bằng khúc xạ kế.

- Năng suất, số quả/cây: Đếm tổng số quả trên 10 cây, tính năng suất trung bình, mỗi cây cân 10 quả tính giá trị trung bình, sau đó tính năng suất cây theo công thức.

+ Năng suất $(\mathrm{kg} / \mathrm{cây})=$ Số quả đậu/cây * Khối lượng trung bình/quả.

\subsubsection{Xư lý số liệu}

Số liệu được xử lý bằng chương trình EXCEL.

\section{Kết quả nghiên cứu và thảo luận}

\subsection{Một số đặc điểm nông sinh học của giống bưởi Xuân Vân}

\subsection{1. Đặc điểm thân cành}

Theo dõi về đặc điểm hình thái trên giống bưởi Xuân Vân tại bảng 3.1 cho thấy: Bưởi Xuân Vân có tán lá hình tựa cầu, tán trải theo chiều rộng, mật độ cành thưa, bề mặt thân cây nhẵn nhụi không có gai, cây được nhân giống bằng phương pháp chiết cành. Chiều cao cây trung bình: $611,8-677,5 \mathrm{~cm}$, chiều rộng tán trung bình: 704,5 - 715,5 cm, đường kính gốc trung bình: $16,69-17,05 \mathrm{~cm}$, độ cao phân cành cấp I trung bình: $40,63-41,38 \mathrm{~cm}$, số lượng cành cấp I: 3,4 cành/cây, số lượng cành cấp II: 9,6 
cành/cây; đường kính cành cấp I trung bình: 9,72 $9,91 \mathrm{~cm}$. Với đặc điểm hình thái mô tả như trên cho thấy: bưởi Xuân Vân là giống bưởi cao cây, diện tích tán lá lớn, vì vậy trong quá trình chăm sóc cần phải được cắt tỉa thường xuyên tạo tán để thuận lợi cho chăm sóc và thu hoạch.

Bảng 3.1: Một số đặc điểm hình thái thân, cành của giống bưởi Xuân Vân

\begin{tabular}{|c|c|c|c|}
\hline \multirow{2}{*}{ Stt } & \multirow{2}{*}{ Chỉ tiêu } & \multicolumn{2}{|c|}{ Mô tả } \\
\hline & & Năm 2015 & Năm 2016 \\
\hline 1 & Hình dạng tán cây & Tựa cầu & Tựa cầu \\
\hline 2 & $\begin{array}{l}\text { Cách phát triển của } \\
\text { cây }\end{array}$ & Trải rộng & Trải rộng \\
\hline 3 & Mật độ cành & Thưa thớt & Thưa thớt \\
\hline 4 & Bề mặt của thân cây & Nhẵn nhụi & Nhẵn nhụi \\
\hline 5 & Mật độ gai & $\begin{array}{l}\text { Không xuất } \\
\text { hiện }\end{array}$ & $\begin{array}{c}\text { Không xuất } \\
\text { hiện }\end{array}$ \\
\hline 6 & $\begin{array}{l}\text { Hình thức nhân } \\
\text { giống }\end{array}$ & Chiết cành & Chiết cành \\
\hline 7 & Chiều cao cây (cm) & $677,5( \pm) 40$ & $611,8( \pm) 42,5$ \\
\hline 8 & Đường kính tán (cm) & $704,5( \pm) 35$ & $715,5( \pm) 30$ \\
\hline 9 & Đường kính gốc (cm) & $16,69( \pm) 1,4$ & $17,05( \pm) 1,35$ \\
\hline 10 & $\begin{array}{l}\text { Độ cao phân cành } \\
(\mathrm{cm})\end{array}$ & $40,63( \pm) 11,36$ & $41,38( \pm) 14$ \\
\hline 11 & $\begin{array}{l}\text { Số lượng cành cấp } 1 \\
\text { (cành) }\end{array}$ & $3,4( \pm) 4$ & $3,4( \pm) 1$ \\
\hline 12 & $\begin{array}{l}\text { Số lượng cành cấp } 2 \\
\text { (cành) }\end{array}$ & $9,6( \pm) 1,5$ & $9,6( \pm) 1,5$ \\
\hline 13 & $\begin{array}{l}\text { Đường kính cành } \\
\text { cấp } 1(\mathrm{~cm})\end{array}$ & $9,72( \pm) 2,5$ & $9,91( \pm) 2,6$ \\
\hline
\end{tabular}

\subsection{2. Đặc điểm hình thái lá bưởi Xuân Vân}

Đặc điểm hình thái lá tại bảng 3.2 cho thấy: Lá bưởi Xuân Vân có chiều dài trung bình: $13,26 \mathrm{~cm}$, chiều rộng phiến lá trung bình: $6,86 \mathrm{~cm}$, tỷ lệ lệ chiều dài/chiều rộng phiến lá: 1,93 , Chiều dài eo lá: $3,28 \mathrm{~cm}$, chiều rộng eo lá: $2,79 \mathrm{~cm}$, tỷ lệ chiều dài trên chiều rộng eo lá: 1,17 , cuống lá có chiều dài trung bình: $0,76 \mathrm{~cm}$. Lá bưởi Xuân Vân có mầu xanh vàng, mép hơi gợn sóng, dạng lá hình trứng, đầu lá tù hơi nhọn.

Bảng 3.2: Đặc điểm hình thái lá bưởi Xuân Vân

\begin{tabular}{|c|c|c|}
\hline $\begin{array}{c}\text { Số } \\
\text { TT }\end{array}$ & Chỉ tiêu & Đặc điểm \\
\hline 1 & Chiều dài phiến lá $(\mathrm{cm})$ & $13,26( \pm) 0,72$ \\
\hline
\end{tabular}

\begin{tabular}{|c|l|l|}
\hline 2 & Chiều rộng phiến lá $(\mathrm{cm})$ & $6,86( \pm) 0,5$ \\
\hline 3 & Chiều dài eo lá $(\mathrm{cm})$ & $3,28( \pm) 0,4$ \\
\hline 4 & Chiều rộng eo lá $(\mathrm{cm})$ & $2,79( \pm) 0,46$ \\
\hline 5 & Chiều dài cuống lá (cm) & $0,76( \pm) 0,025$ \\
\hline 6 & Tỷ lệ chiều dài/chiều rộng (phiến lá) & $1,93( \pm) 0,15$ \\
\hline 7 & Tỷ lệ chiều dài/chiều rộng (eo lá) & $1,17( \pm) 0,17$ \\
\hline 8 & Mầu sắc lá & Xanh vàng \\
\hline 9 & Mép lá & Gợn sóng \\
\hline 10 & Hình dạng lá & Hình trứng \\
\hline 11 & Đầu lá & Tù hơi nhọn \\
\hline
\end{tabular}

3.1.3. Đặc điểm hình thái hoa, thời gian nở hoa của giống bưởi Xuân Vân

Đặc điểm hình thái hoa hoa bưởi Xuân Vân tại bảng 3.3 cho thấy: Hoa bưởi Xuân Vân có mầu trắng sáng, dạng hoa chủ yếu là hoa chùm và hoa đơn. Hoa bưởi Xuân Vân có số cánh trung bình trên hoa: 4,294,32 cánh, số chỉ nhị trung bình: 28,09-28,11chỉ nhị/hoa, chiều dài hoa trung bình: $2,25-2,27 \mathrm{~cm}$, đường kính hoa trung bình: 0,72-0,74 cm.

Năm 2015 thời gian xuất hiện nụ hoa trong khoảng thời gian từ ngày 25 tháng 1 đến ngày 2 tháng 2 , thời gian hoa nở trong khoảng thời gian từ ngày 10 đến ngày 17 tháng 2 , thời gian hoa nở rộ trong khoảng thời gian từ ngày 18 tháng 2 đến ngày 27 tháng 2 , thời gian kết thúc nở hoa trong khoảng thời gian từ ngày 5 tháng 3 đến ngày 8 tháng 3 , thời gian từ khi nở hoa đến kết thúc nở hoa năm 2015 kéo dài từ 22 đến 27 ngày.

Năm 2016 thời gian xuất hiện nụ hoa trong khoảng thời gian từ ngày 28 tháng 1 đến ngày 10 tháng 2 , thời gian hoa nở trong khoảng thời gian từ ngày 14 đến ngày 21 tháng 2 , thời gian hoa nở rộ trong khoảng thời gian từ ngày 22 tháng 2 đến ngày 3 tháng 3 ; thời gian kết thúc nở hoa trong khoảng thời gian từ ngày 3 tháng 3 đến ngày 13 tháng 3 , thời gian từ khi nở hoa đến kết thúc nở hoa trong năm 2016 kéo dài từ 22 đến 27 ngày. 
Bảng 3.3: Đặc điểm hoa bưởi Xuân Vân

\begin{tabular}{|c|c|c|c|}
\hline \multirow[t]{2}{*}{ Stt } & \multirow[t]{2}{*}{ Chỉ tiêu } & \multicolumn{2}{|c|}{ Năm } \\
\hline & & 2015 & 2016 \\
\hline 1 & Mầu sắc hoa & Trắng sáng & Trắng sáng \\
\hline 2 & Dạng hoa & $\begin{array}{l}\text { Hoa chùm, hoa } \\
\text { đơn }\end{array}$ & $\begin{array}{l}\text { Hoa chùm, } \\
\text { hoa đơn }\end{array}$ \\
\hline 3 & Số cánh hoa/hoa (hoa) & $4,32( \pm) 0,13$ & $4,29( \pm) 0,14$ \\
\hline 4 & Số chỉ nhị/hoa (chỉ nhị) & $28,11( \pm) 0,65$ & $28,09( \pm) 0,61$ \\
\hline 5 & Chiều dài hoa $(\mathrm{cm})$ & $2,27( \pm) 0,21$ & $2,25( \pm) 0,23$ \\
\hline 6 & Đường kính hoa (cm) & $0,74( \pm) 0,12$ & $0,72( \pm) 0,11$ \\
\hline 7 & $\begin{array}{l}\text { Thời gian xuất hiện } \\
\text { nụ hoa }\end{array}$ & $25 / 1-2 / 2$ & $28 / 1-10 / 2$ \\
\hline 8 & Thời gian hoa nở & $10-17 / 2$ & $14-21 / 2$ \\
\hline 9 & Thời gian nở rộ & $18 / 2-27 / 2$ & $22 / 2-3 / 3$ \\
\hline 10 & Thời gian kết thúc & $5 / 3-8 / 3$ & $3 / 3-13 / 3$ \\
\hline 11 & $\begin{array}{l}\text { Thời gian từ nở hoa đến } \\
\text { kết thúc nở hoa (ngày) }\end{array}$ & 22 - 27 ngày & 22 - 27 ngày \\
\hline
\end{tabular}

3.1.4. Đặc điểm hình thái quả, thời vu thu hoạch, năng xuất và một số chỉ tiêu trên quả

Đặc điểm hình thái quả: bưởi Xuân Vân có dạng quả hình cầu, vỏ quả có mầu vàng nhạt, trục quả rỗng, tép có mầu vàng nhạt, giòn, dễ lột với vỏ múi, mùi vị thơm.

Các yếu tố cấu thành năng suất: bưởi Xuân Vân có trọng lượng quả trung bình từ 906,9 đến 912,1 gam, số quả từ 96,5 đến 142,3 quả/cây, năng suất trung bình từ 87,96 - $128,93 \mathrm{~kg} /$ cây.

Một số chỉ tiêu trên quả: bưởi Xuân Vân có đường kính quả từ 12,91 đến $12,94 \mathrm{~cm}$, chiều cao quả từ 11,79 đến $11,8 \mathrm{~cm}$, số hạt từ 122,9 đến 124,56 hạt/quả, số múi từ 13,4 đến 13,43 múi/quả. Bưởi Xuân
Vân có độ Brix: 10,93 - 10,97\%, tỷ lệ phần ăn được: $52,4-53,32 \%$.

Bảng 3.4: Đặc điểm hình thái, thời vụ thu hoạch, năng suất và một số chỉ tiêu trên quả

\begin{tabular}{|c|c|c|c|}
\hline \multirow[t]{2}{*}{ Stt } & \multirow[t]{2}{*}{ Chỉ tiêu } & \multicolumn{2}{|c|}{ Năm } \\
\hline & & 2015 & 2016 \\
\hline 1 & Hình dạng quả & Hình cầu & Hình cầu \\
\hline 2 & Mầu sắc vỏ quả & Vàng nhạt & Vàng nhạt \\
\hline 3 & Trục quả & Rỗng & Rỗng \\
\hline 4 & Mầu sắc tép & Vàng nhạt & Vàng nhạt \\
\hline 5 & Độ giòn của tép & Giòn & Giòn \\
\hline 6 & $\begin{array}{l}\text { Độ bám của vỏ } \\
\text { múi với tép }\end{array}$ & Dễ lột & Dễ lột \\
\hline 7 & Đánh giá & Rất ngon & Rất ngon \\
\hline 8 & $\begin{array}{l}\text { Thời vụ thu } \\
\text { hoạch (tháng) }\end{array}$ & $\begin{array}{l}\text { Cuối tháng } 9 \\
\text { dầu tháng } 10\end{array}$ & $\begin{array}{l}\text { Cuối tháng } 9 \\
\text { dầu tháng } 10\end{array}$ \\
\hline 9 & $\begin{array}{l}\text { Trọng lượng } \\
\text { quả }(\mathrm{kg})\end{array}$ & $0,912( \pm) 35,5$ & $0,906( \pm) 30,5$ \\
\hline 10 & $\begin{array}{l}\text { Số lượng } \\
\text { quả/cây (quả) }\end{array}$ & $96,5( \pm) 26,5$ & $142,3( \pm) 18,5$ \\
\hline 11 & $\begin{array}{ll}\text { Năng } & \text { suất } \\
\text { (kg/cây) } & \end{array}$ & $88,0( \pm) 23,5$ & $128,9( \pm) 12,8$ \\
\hline 12 & $\begin{array}{l}\text { Đường kính quả } \\
(\mathrm{cm})\end{array}$ & $12,91( \pm) 1,2$ & $12,94( \pm) 1,1$ \\
\hline 13 & $\begin{array}{l}\text { Chiều cao quả } \\
(\mathrm{cm})\end{array}$ & $11,79( \pm) 0,9$ & $11,8( \pm) 0,9$ \\
\hline 14 & Số hạt/quả (hạt) & $122,9( \pm) 15$ & $124,6( \pm) 11,5$ \\
\hline 15 & $\begin{array}{l}\text { Số múi trên quả } \\
\text { (múi) }\end{array}$ & $13,43( \pm) 1,5$ & $13,4( \pm) 1$ \\
\hline 16 & Độ Brix (\%) & $10,97( \pm) 0,76$ & $10,93( \pm) 0,5$ \\
\hline 17 & $\begin{array}{l}\text { Tỷ lệ phần ăn } \\
\text { được (\%) }\end{array}$ & $53,2( \pm) 4,3$ & $52,4( \pm) 4,05$ \\
\hline
\end{tabular}

\section{Kết luận và đề nghị}

\subsection{Kết luận}

- Bưởi Xuân Vân có chiều cao cây trung bình: 611,8 - 677,5 cm, đường kính tán trung bình: 704,5 đến 715,5 $\mathrm{cm}$. Thời gian từ khi hoa nở đến kết thúc nở hoa kéo dài: 22 - 27 ngày, thời điểm thu hoạch từ cuối tháng 9 đầu tháng 10 .

- Bưởi Xuân Vân có trọng lượng quả trung bình: 0,906 - 0,912, số lượng quả trung bình: 96,5 - 142,3 quả/cây, năng suất trung bình: 88,0 - 128,9 kg/cây. 
- Bưởi Xuân Vân có số hạt trung bình: 122,9 đến 124,7 hạt/quả, số múi trung bình: 13,4 - 13,43 múi/quả, độ Brix trung bình: 10,93 - 10,97\%, tỷ lệ phần ăn được trung bình: 52,4 - 53,2\%.

\section{2. Đề nghi}

Đề nghị Sở Nông nghiệp và Phát triển Nông thôn tỉnh Tuyên Quang hướng dẫn khoảng cách trồng đối với bưởi Xuân Vân: 7-8 m/cây, với mật độ trồng: 160205 cây/ha.

\section{TÀI LIỆ THAM KHẢO}

1. Ngô Xuân Bình, Kỹ thuật trồng bưởi, Nxb Nông Nghiệp, Hà Nội, 2010;
2. Cục Thống kê Tuyên Quang, Số liệu Thống kê nông lâm nghiệp - thuỷ sản, Nxb, Hà Nội, 2016;

3. Nguyễn Hữu Thọ, Nghiên cúu đặc điểm nông sinh học và một số biện pháp kỹ thuật đối với giống bươi diễn (citrus grandis) tại tỉnh Thái Nguyên, Luận án Tiến sĩ Nông nghiệp, 2015;

4. Trần Thế Tục, Giáo trình cây ăn quả, Nxb Nông nghiệp, Hà Nội, 1998;

5. Đỗ Năng Vịnh, Cây ăn quả có múi công nghệ sinh hoc chọn tạo giống, Nxb Nông nghiệp, Hà Nội, 2008;

6. IBPGR, Descriptors for citrus, International Plant Genetic Resources Institute, 1999.

\title{
Study on agro-biological characteristics of Xuan Van pumelo variety in Tuyen Quang province
}

\author{
Vi Xuan Hoc; Nguyen Quoc Hung; Pham Thi Mai Trang
}

\section{Article info}

\section{Recieved:}

11/10/2017

Accepted:

$10 / 3 / 2018$

\section{Keywords:}

Xuan Van pomelo; agro-biological characteristics.

\begin{abstract}
Xuan Van pomelo is a sweet early-ripening pomelo variety of Tuyen Quang province, Xuan Van pomelo originated from Soi Ha village, Xuan Van commune, Yen Son district. In order to have scientific basis and identify appropriate technical measures to improve the quality of Xuan Van pomelo fruit in a sustainable manner, research on agro-biotech characteristics is very necessary. Research results in 2015-2016 on agro-biological characteristics of Xuan Van pomelo variety show that the tree height is from 611.8 to $677.5 \mathrm{~cm}$; the canopy and root diameters are from 704.5 to $715.5 \mathrm{~cm}$ and 16.99 to 17.05 $\mathrm{cm}$ respectively; Flowers often bloom from the $10^{\text {th }}$ to the $21^{\text {st }}$ of February and cease to bloom from the $5^{\text {th }}$ to $13^{\text {th }}$ of March, the time from blossoming to offstage lasts from 22 to 27 days. The fruit weight is from 0,906 to 0,912 kilograms, the average fruit number ranges from 96,5 to 142,3 fruits/tree, with an average yield of $88,0-128.9 \mathrm{~kg} /$ tree. Number of seeds from 122.9 to 124.6 seeds per fruit, average number of pods from 13.4 to 13.43 pods per pod, Brix level is from $10.93-10.97 \%, 52.4-53.2 \%$ of which can be edible.
\end{abstract}

